\title{
COVID-19-associated pancreatic dysfunction
}

\author{
Adel Abdel-Moneim *, PhD
}

Molecular Physiology Division, Faculty of Science, Beni-Suef University, Beni-Suef, Egypt

* Corresponding author: adel.hassan@science.bsu.edu.eg

Hong Kong Med J 2021;27:157-9

https://doi.org/10.12809/hkmj209056

\section{Introduction}

Although coronavirus disease 2019 (COVID-19) is mainly considered a lower respiratory tract infection, the disease can induce dysfunction in multiple organs, including the kidney, heart, liver, gut, and pancreas. ${ }^{1}$ Other viral diseases, such as human immunodeficiency virus, mumps, cytomegalovirus, coxsackievirus B and influenza A (H1N1), have been reported to cause acute pancreatic inflammation. ${ }^{2}$ The severe acute respiratory syndrome coronavirus 2 (SARS-CoV-2) that causes COVID-19 uses angiotensin-converting enzyme 2 (ACE2) receptors for invading the tissue cells and primarily spreads via the respiratory tract. The clinical signs of patients with COVID-19 usually include fever, cough, fatigue, and some patients have shown symptoms of gastrointestinal disturbance. ${ }^{3}$ However, acute liver injury in patients with COVID-19 is independently associated with adverse clinical outcomes. ${ }^{4}$ Little is known about the influence of SARS-CoV-2 in pancreatic injury. Herein this study discusses the current evidence for the effect of COVID-19 on pancreatic function.

\section{Coronavirus disease 2019 and pancreatic manifestations}

Some associations between COVID-19 and acute pancreatitis have been reported. In a clinical study, two family members admitted to intensive care unit with COVID-19 were identified with acute pancreatitis. ${ }^{5}$ In one study in China, of 67 patients with severe COVID-19, 12 patients (17.9\%) had elevated amylase levels, 11 patients $(16.4 \%)$ had elevated lipase levels, and five patients (7.5\%) had notable imaging features (focal enlargement of the pancreas or dilatation of the pancreatic duct). ${ }^{6}$ In addition, 2\% of patients with non-severe COVID-19 had elevated lipase and amylase levels. ${ }^{6}$ In another study in China, elevated amylase levels were reported in 19 patients with COVID-19 admitted to the intensive care unit.? In a cohort of 11883 patients with COVID-19 in the United States, 32 patients met the criteria for a diagnosis of pancreatitis. ${ }^{8}$ In another study in the United States, 14 (18.7\%) out of 75 patients with COVID-19 met the criteria for a diagnosis of acute pancreatitis. ${ }^{9}$ Although acute pancreatitis is rarely confirmed in patients with COVID-19, four cases of acute pancreatitis have been confirmed in different three studies after careful exclusion of other factors, highlighting a possible role of COVID-19 as an aetiological factor for acute viral pancreatitis. ${ }^{10-12}$

Elevated levels of pancreatic enzymes without clinical evidence of pancreatitis have been reported in patients with COVID-19. ${ }^{13}$ Patients with COVID-19 may experience symptoms associated with high pancreatic enzyme levels, such as gut inflammation, diabetes, and kidney diseases. ${ }^{14}$ Additionally, gastroenteritis is a well-known cause of elevated pancreatic enzymes ${ }^{15}$ and such elevation could be explained by raised intestinal permeability in response to inflammation, which promotes the reabsorption of macromolecules, such as amylase and lipase. ${ }^{16}$

In a study in China of 52 patients with COVID-19, nine (17.3\%) patients had abnormal amylase or lipase levels, six of whom developed hyperglycaemia without pre-existing diabetes. ${ }^{17}$ Furthermore, SARS-CoV-2 infection of the surrounding exocrine pancreas can generate islet cell injury through the release of proinflammatory cytokines. ${ }^{18}$ Owing to the structural and syndromic similarities between SARS-CoV-2 and SARS-CoV, it is reasonable to consider evidence that SARS-CoV infection can destroy islets cells, leading to decreased insulin release: 3 years after recovery from SARS-CoV infection, up to $5 \%$ of patients develop diabetes. ${ }^{19}$ In three patients with COVID-19, Yao et al ${ }^{20}$ found that few pancreatic islet cells in the autopsy pancreas have degenerated with a normal exocrine pattern. Recently, a survey of 1122 hospitalised patients with COVID-19 indicated uncontrolled hyperglycaemia in 257 of them. ${ }^{21}$ Thus, similar to SARS-CoV infection, pancreatic injury may be associated with COVID-19 complications.

\section{Coronavirus disease 2019 and pathogenic mechanisms}

Autopsy reports from four patients with SARS-CoV infection identified SARS-CoV RNA in pancreatic tissues. ${ }^{22}$ Coronaviruses such as SARS-CoV and SARS-CoV-2 enter target cells via the ACE2 receptor. Therefore, expression of ACE2 in any organ 
may provide a pathway for SARS-CoV-2 infection leading to tissue injury. ${ }^{23}$ Notably, ACE2 is expressed in the exocrine glands and islets of the pancreas and the damage is proportional to the severity of SARS-CoV-2 infection. ${ }^{6}$ Abundant expression of ACE2 in human islets has been reported. ${ }^{23}$

In patients with severe COVID-19, the expression of ACE2 in the pancreas during SARS-CoV-2 infection can result in acute inflammation which caused acute pancreatitis. ${ }^{5}$ However, there are other possible causes of pancreatic injury in patients with COVID-19. Acute pancreatitis has also been reported as an adverse effect of lopinavir-ritonavir, a treatment for patients with COVID-19. ${ }^{24}$ Similarly, antipyretics, which the patient may have taken before admission, can cause pancreatic injury. ${ }^{17} \mathrm{~A}$ mild rise in blood pancreatic enzymes in patients with COVID-19 can also result from causes other than pancreatic damage. ${ }^{14}$

For intensive care unit clinicians making admission decisions, predicting the severity of acute pancreatitis is important. Validated scoring systems, including Ranson's score, the updated Glasgow score, the harmless acute pancreatitis score, and the bedside index for severity of acute pancreatitis, have been used for predicting the severity and mortality of acute pancreatitis during presentation and admission. Among them, Ranson's score diagnostic accuracy on admission is higher for prediction of severity, organ failure, and mortality based on receiver operator characteristic curves. ${ }^{25,26}$ These scoring systems may be used for predicting the severity and mortality of acute pancreatitis in patients with COVID-19.

\section{Conclusions}

Pancreatic dysfunction may be related to SARS-CoV-2 infection by direct invasion of the pancreatic cells or secondarily by tissue damage caused by the systemic inflammatory immune response or even by medication prescribed to treat severe cases of COVID-19. Clinicians should be aware of the possibility of pancreatic dysfunction in patients with COVID-19, and should take appropriate precautions if patients show relevant signs or symptoms.

\section{Author contributions}

The author contributed to the concept or design of the study, acquisition of the data, analysis or interpretation of the data, drafting of the manuscript, and critical revision of the manuscript for important intellectual content. The author had full access to the data, contributed to the study, approved the final version for publication, and takes responsibility for its accuracy and integrity.

\section{Conflicts of interest}

The author has disclosed no conflicts of interest.

\section{References}

1. Ni W, Yang X, Yang D, et al. Role of angiotensin-converting enzyme 2 (ACE2) in COVID-19. Crit Care 2020;24:422.

2. Lankisch PG, Apte M, Banks PA. Acute pancreatitis. Lancet 2015;386:85-96.

3. Guo YR, Cao QD, Hong ZS, et al. The origin, transmission and clinical therapies on coronavirus disease 2019 (COVID-19) outbreak-an update on the status. Mil Med Res 2020;7:11.

4. Hadi A, Werge M, Kristiansen KT, et al. Coronavirus Disease-19 (COVID-19) associated with severe acute pancreatitis: case report on three family members. Pancreatology 2020;20:665-7.

5. Yip TC, Lui GC, Wong VW, et al. Liver injury is independently associated with adverse clinical outcomes in patients with COVID-19. Gut 2020 Jul 8. Epub ahead of print.

6. Liu F, Long X, Zhang B, Zhang W, Chen X, Zhang Z. ACE2 expression in pancreas may cause pancreatic damage after SARS-CoV-2 infection. Clin Gastroenterol Hepatol 2020;18:2128-30.e2.

7. Zhang J, Liu P, Wang M, et al. The clinical data from 19 critically ill patients with coronavirus disease 2019: a single-centered, retrospective, observational study. Z Gesundh Wiss 2020 Apr 21. Epub ahead of print.

8. Inamdar S, Benias PC, Liu Y, et al. Prevalence, risk factors, and outcomes of hospitalized patients with COVID-19 presenting as acute pancreatitis. Gastroenterology 2020 Aug 26. Epub ahead of print.

9. Dirweesh A, Li Y, Trikudanathan G, Mallery JS, Freeman ML, Amateau SK. Clinical outcomes of acute pancreatitis in patients with COVID-19. Gastroenterology 2020 Jul 25. Epub ahead of print.

10. Wang K, Luo J, Tan F, et al. Acute pancreatitis as the initial manifestation in 2 cases of COVID-19 in Wuhan, China. Open Forum Infect Dis 2020;7:ofaa324.

11. Kumaran NK, Karmakar BK, Taylor OM. Coronavirus disease-19 (COVID-19) associated with acute necrotising pancreatitis (ANP). BMJ Case Rep 2020;13:e237903.

12. Alves AM, Yvamoto EY, Marzinotto MA, Teixeira AC, Carrilho FJ. SARS-CoV-2 leading to acute pancreatitis: an unusual presentation. Braz J Infect Dis 2020 Sep 15. Epub ahead of print.

13. McNabb-Baltar J, Jin DX, Grover AS, et al. Lipase elevation in patients with COVID-19. Am J Gastroenterol 2020;115:1286-8.

14. de-Madaria E, Siau K, Cárdenas-Jaén K. Increased amylase and lipase in patients with COVID-19 pneumonia: don't blame the pancreas just yet! Gastroenterology 2020 Apr 21. Epub ahead of print.

15. Tositti G, Fabris P, Barnes E, et al. Pancreatic hyperamylasemia during acute gastroenteritis: incidence and clinical relevance. BMC Infect Dis 2001;1:18.

16. Pieper-Bigelow C, Strocchi A, Levitt MD. Where does serum amylase come from and where does it go? Gastroenterol Clin North Am 1990;19:793-10.

17. Wang F, Wang $H$, Fan J, Zhang Y, Wang $H$, Zhao Q. Pancreatic injury patterns in patients with Coronavirus Disease 19 pneumonia. Gastroenterology 2020;159:36770.

18. Lazartigues E, Qadir MM, Mauvais-Jarvis F. Endocrine significance of SARS-CoV-2's reliance on ACE2. Endocrinology 2020;161:bqaa108. 
19. Yang JK, Lin SS, Ji XJ, Guo LM. Binding of SARS coronavirus to its receptor damages islets and causes acute diabetes. Acta Diabetol 2010;47:193-9.

20. Yao XH, Li TY, He ZC, et al. A pathological report of three COVID-19 cases by minimally invasive autopsies [in Chinese]. Zhonghua Bing Li Xue Za Zhi 2020;49:411-7.

21. Bode B, Garrett V, Messler J, et al. Glycemic characteristics and clinical outcomes of COVID-19 patients hospitalized in the United States. J Diabetes Sci Technol 2020;14:81321.

22. Ding Y, He L, Zhang Q, et al. Organ distribution of severe acute respiratory syndrome (SARS) associated coronavirus (SARS-CoV) in SARS patients: implications for pathogenesis and virus transmission pathways. J Pathol
2004;203:622-30

23. Wu F, Zhao S, Yu B, et al. A new coronavirus associated with human respiratory disease in China. Nature 2020;579:2659.

24. Chapman SJ, Woolley IJ, Visvanathan K, Korman TM. Acute pancreatitis caused by tipranavir/ritonavir-induced hypertriglyceridaemia. AIDS 2007;21:532-3.

25. Kuo DC, Rider AC, Estrada P, Kim D, Pillow MT. Acute pancreatitis: what's the score? J Emerg Med 2015;48:76270.

26. Venkatesh NR, Vijayakumar C, Balasubramaniyan G, et al. Comparison of different scoring systems in predicting the severity of acute pancreatitis: a prospective observational study. Cureus 2020;12:e6943. 